\title{
Speeding behaviour of adolescents and the image of a typical person who speeds
}

\section{Sonja E. Forward}

Swedish Road and Transport Research Institute, VTI, 58195 Linköping, Sweden; sonja.forward@vti.se

\begin{abstract}
The aim of this study was to increase our understanding of what motivates young people to take risks in traffic but also why young men are more likely to get involved in road crashes.
\end{abstract}

The participants aged 16-19 years ( $N=945)$ completed an online survey. The questions were influenced by the Theory of planned behaviour (TPB) and the Prototype willingness model (PWM) and included a scenario describing a person riding a moped at $65 \mathrm{~km} / \mathrm{h}$ in an urban area, in which the speed limit was $50 \mathrm{~km} / \mathrm{h}$.

The results, using a regression analysis, showed that a model which explained their willingness to speed was slightly better than a model explaining their intention. The best predictor, according to the beta weights in both models, was that it was "fun". However, this variable was more important in explaining their willingness than their intention. Other similar factors describing emotions with immediate rewards were also significantly more important in the prediction of willingness than intention.

When analysing the willingness to speed amongst young men and women, the results presented both similar and different results. Both were heavily influenced by a belief that it would be "fun". However, only young men also believed that it would impress others and that it would make them popular. Young women on the other hand did not believe that the behaviour was particularly boylike which could explain why they could identify with a person who sped.

The conclusion, from this study, is that speeding can be described as a reactive behaviour, but it could not be ruled out that it also can be planned. Based on the results from this study it is concluded that TPB would benefit from the inclusion of PWM variables.

KEYWORDS: Prototype willingness model, Theory of planned behaviour, risk perception, young drivers, speeding, gender.

\section{INTRODUCTION}

Every year 3800 young drivers are killed on EU roads (ETSC, 2017) and for this group road crashes are the biggest single cause of death. A large number of road crashes are related to speeding (Hassan \& Abdel-Aty, 2013; Mohammed \& Bromfield, 2017; Watters \& Beck, 2016). Indeed, in the study by Watters and Beck (2016), participants believed that driving too slowly was more dangerous than driving too fast. Lack of experience and age, can to some extent, explain increased risk since their involvement in road crashes is reduced during the first six months after receiving their driving license (Mayhew, Simpson, $\&$ Pak, 2003). However, this is not the only explanation since psychological factors, including; overestimation of own driving skills, poor risk perception and mood have been associated with road crashes (Cestac, Paran, \& Delhomme, 2011; Horvath, Lewis \& Watson, 2012; Iversen, 2004; Oviedo-Trespalacios, \& Scott-Parker, 2018; Rowe, et. al., 2016).

The aim of this study was, with the help of two different theoretical frameworks (TPB and PWM), to assess social and psychological factors underpinning risky behaviour in traffic. An attempt was also made to analyse if the motives behind the action differed between young men and women.

\subsection{Influenced by others}

It is well known that parents influence their children at an early age and that they act as role models, which may be both positive and negative (Scott-Parker, Watson \& King, 2009; Summala, 1996). This also includes driver behaviour since parents influence their children through their own behaviour in traffic. For example, in a US study, a link could be made between parents and their child when it came to accident involvement but also traffic violations (Ferguson, et al., 2001). 
However, even if parents are more important during early adulthood it would appear that peers are even more important (Arata, Stafford \& Tims, 2003). In a study by Simons-Morton et al. (2012) having risky friends was the only significant variable which predicted speeding.

However, peer pressure does not always result in risky driving since it depends on the norms within the group and in some instances, it could also protect people from risky driving (Engström, 2008; Guggenheim \& Taubman - Ben-Ari, 2015; Rueda-Domingo et al., 2004; Shope \& Bingham, 2008; Vollrath, Meilinger \& Krüger, 2002). According to Engström, (2008) group cohesion is thus an important factor determining how driver behaviour develops, positively or negatively. For instance, young people who believe that their friends disapprove of drinking and driving are less likely to do the same (Grube \& Voas, 1996).

Nevertheless, the choice of friends can also be regarded as an active process, this would then mean that they mix with friends who are most like themselves. This was something Simons-Morton et al. (2012) found in their study, they argued that adolescents already prone to risky driving would choose friends with similar attitudes and behaviour. In addition to this, having risky friends might also lower the perceptions of risk which could further exacerbates the problem. An alternative explanation provided by the same authors would be that risky friends could affect the behaviour of young drivers through overt pressure, encouraging risky behaviour.

Peer pressure could therefore be either, direct or indirect. For instance, peers might verbally encourage the driver to violate or make them to violate because he/she believes that others think they should violate, which could be true or false. This was also illustrated by Taubman - Ben-Ari, et al (2015) who showed that there was a link between a belief that risky driving would make them (in this case young male drivers), popular. Hence, if the behaviour is sanctioned by the peer group the driver is also more likely to engage in risky driving which in turn helps them to achieve a higher social standing within the group (Weston \& Hellier, (2018). In an earlier study Miller (2004) argued along similar lines, stating that the young person can achieve a certain status and position within the group if he/she conforms to a shared norm. It could therefore be stated that it is the combination of attitudes (belief that the behaviour has a positive outcome) and norms (friends approve of the behaviour) which helps to explain the impact of peer pressure.

\subsection{Social identiy}

The behaviour of young drivers can also be explained by the "social identity theory" (Stainton Rogers, 2003). This theory states that a person's social identity is created by the group in which the individual is included, for example different interest groups. According to this theory, an individual's identity is under constant creation, which in turn is influenced by the contexts and interactions with others. Worchel et al (1998) argued that in the context of group formation, an initial form of identity is established, and relationships are defined, both within the group and in other groups. The group's identity can be reproduced in terms of its values, where symbols and the language used within the group reflects the group's identity.

\subsection{Gender}

Research has also found that there is a relatively large difference between young men and women and that it is men, rather than women, who are more likely to get involved in a road crash (Oltedal \& Rundmo, 2006; Transport Analysis, 2019; Whissell \& Bigelow, 2003).

The reason for the difference between young men and women is a topic widely discussed and many times it is about the link between testosterone and risk taking (Eisenegger, Haushofer \& Fehr, 2011). This is because significant hormonal changes occur during puberty, especially for boys. Therefore, many have assumed that men's risk-taking is linked to this hormone (Bogaert \& Fisher, 1995).

However, in a study by Duke, Balzer and Steinbeck (2014), which included 27 different studies, the effect of testosterone on the behavior of boys aged 9-18 was examined. The results showed that there was insufficient evidence to substantiate the association between testosterone and behavioral changes (see also Fausto-Sterling, 1992; Fine, 2017). Other studies that examined the association between sensation seeking and testosterone are not conclusive since some have found a relationship and others have not (see Campbell, et al., 2010). It is also worth noting that very few studies have studied the relationship between women, hormones and sensation seekers. For this reason, very little is known about what affects women's sensation seeking (de Almeida, Cabral \& Narvaes, 2015). The results from studies therefore indicates that young men's risk-taking is more complex and that it has a strong psychosocial explanation. 
One reason for this gender difference could be that young men tend to be more optimistic than young females and therefore rate risky driving as less serious (DeJoy, 1992) but also that they believe themselves not to be as vulnerable as female drivers (Harré, Field, \& Kirkwood, 1996). Such perceptions, in turn, could perhaps be linked to gender identity and as Farrow and Brissing (1990) pointed out, many men regard the car as a way of expressing their own masculinity and one aspect of which defines masculinity is being fearless.

Being a man or woman not only means being an individual but also to belong to a group that is expected to share the same characteristics (Grace, David, \& Ryan, 2008). Gender can help in understanding how he or she should behave in a socially expected way. Studies have shown that children already at the age three can classify items based on whether they are linked to the male or female (Banse, et. al., 2010). Young children also tend to imitate others of the same gender as themselves. This is especially true of boys who often annoy others if they do not behave according to the current gender norm (Grace, et al., 2008). Thus, to avoid being punished they are encouraged to comply with the norms which can result in a selffulfilling prophecy.

However, it is important to recognise that within group differences also exist, meaning that groups are not homogenous. Although Geber, Baumann and Klimmt (2016) found that the highly risk-motivated group consisted of mostly men, this group was the smallest, representing only 19 percent of young drivers. Instead, it was the group described as less risk-motivated which represented the greatest percentage (32\%).

It could therefore be argued, that it would be more productive to talk about driver behaviour in terms of gender roles rather than hormones and biological sex.

\subsection{Theoretical framework}

The design of this study is influenced by two theoretical models: Theory of Planned Behaviour (TPB) and The Prototype Willingness model (PWM). The combination of these two models has been very successful in studies of individuals, particularly young people and risky behaviour (see e.g. Gerrad et al, 2008; Gibbons, Houlihan \& Gerrard, 2009). Studies of this kind can also serve as a basis for various interventions (Rivis, Sheeran \& Armitage, 2006).
The TPB predicts that a person's behaviour is a function of behavioural intention, which in turn is a function of attitude, subjective norm and perceived behavioural control (Ajzen, 1991). Intention has a central role within the TPB and is generally regarded as a sufficiently immediate cause of behaviour. Attitude describes respondents' positive or negative evaluation of the behaviour. Subjective norm is described as individuals' perception about other people's reaction to them performing or not performing a certain behaviour. A reaction sometimes described as a form of social pressure (Ajzen \& Fishbein, 2005; Albarracín et al., 1990). This would then be followed by compliance, if the individual accepts their influence. The TPB posits that an act can only be performed if the person also has access to a number of different factors (e.g., skills, opportunities, resources). To assess these factors may be difficult but the theory asserts that it can be measured indirectly via a person's belief about how easy or difficult the performance of an act is likely to be, that is, perceived behavioural control. In general, it should capture if the respondent feels confident about his/her ability to perform the behaviour.

PWM is another model that helps in predicting road user behaviour. As described above, intention is an important factor within the TPB. The PWM does not contradict this, indeed intention is also included in the model, but it also added a measure, described as a willingness to act (see Gibbons, Gerrard, Blanton \& Russell, 1998). According to Gibbons, et al. (2009) speeding might involve some forethought(s) and would therefore be planned. In this instance behavioural intention might also be able to predict such a behaviour. However, they also identify several behaviours which are more spontaneous, such as driving after heavy drinking, and in this instance, the link between behaviour and intentions might not be so strong. This might be especially true for adolescents, who tend to be less deliberate, in their decision making. In order to improve the predictive value, of especially adolescents health risk behaviour, it included two pathways to behaviour; one intentional, which is more reasoned and the other which are less deliberate i.e. behavioural willingness (Gibbons et al, 2006). The latter pathway has also been described as a social reactive pathway (Gibbons et al, 1998). Indirect factors which affect intention and their willingness to act is in accordance with the TPB attitude and subjective norm. However, the PWM also include the perception of a person who commits the behaviour, for 
instance is the typical person who speeds clever? The rationale behind this is that health risk behaviour is usually carried out with others and therefore the image of such a person is important.

In addition to this the PWM includes measures of how similar the person believe they are to this person and if they like that person or not (prototype similarity and prototype favourability). Studies have shown that if the image of someone performing a risky behavior is positive then the person is more likely to do the same, despite any negative consequences (Blanton, Gibbons, Gerrard, Conger \& Smith, 1997). The theory has been used together with the TPB and the results showed that variables from the PWM increased the predictive validity of the TPB (Elliott, et al, 2017; Rivis, et al, 2006).

It could therefore be argued that both the TPB and the PWM assume that humans are governed by so called 'rational thinking' although the latter model also takes a more heuristic approach and acknowledges that the individual in some cases act spontaneously without careful consideration, which might be especially relevant when studying young people.

\subsection{Aims}

The present study aimed to use two different theoretical frameworks (TPB and the PWM) to examine factors influencing young moped riders' propensity to speed in an urban area, including two pathways, one intentional and one social reactive. It also examined if the variables within the PWM adds significantly to the prediction of adolescents' speeding behaviour. A further aim was to examine what factors predict young men and women's speeding behaviour.

\section{METHOD}

\subsection{Participants}

The sample was drawn from the Swedish Transport Agency's licence register and consisted of 945 people (43\% female) aged between 16 to 19 years $\left(\mathrm{M}_{\text {age }}=18\right)$. The respondents were regular users of the moped with a large proportion using it several times a week (69\%).

\subsection{Procedure}

A postcard was sent to the persons selected, including an invitation to participate in the study. The card referred to a temporary site, www.vti.se/mopedenkat, where instructions were given on how the person could get access to the survey, using a special code that was printed on the post card. After the initial invitation two reminders were sent out which resulted in a response rate of $62 \%$. After returning the completed survey, they received a cinema voucher.

\subsection{Measures}

The questions in the survey were inspired by the TPB and the PWM, some of them being based on questions previously used with the same target group (Berg, Forward \& Holgersson, 2008).

The survey included one scenario with clear descriptions, to which the respondents were asked to react. It described a situation involving a person riding a moped at $65 \mathrm{~km} / \mathrm{h}$ in a built-up area in which the speed limit was $50 \mathrm{~km} / \mathrm{h}$. This means that the scenario depicts two crimes; one is the act of speeding and the other is riding a moped in which the restriction of speed has been removed. The penalty for the latter is a fine and the police can also repossess the moped. The respondent was asked to imagine themselves in the depicted situation, even if he/she would not act according to the description. The description of the scenario was as follows:

Imagine that it is in the month of May and that you are riding a moped in an urban area. The speed limit is $50 \mathrm{~km} / \mathrm{h}$. On the road there are some other cars, buses and bikes. You are riding your moped at a speed of $65 \mathrm{~km} / \mathrm{h}$.

The description of this situation was followed by various statements and all the responses to the items included in the questionnaire were measured on a unipolar scale $(+1$ to +7$)$.

\section{TPB variables}

Attitudes toward speeding in an urban area were assessed by four items: To drive at $65 \mathrm{~km} / \mathrm{h}$ in an urban area is "fun", If I drive at $65 \mathrm{~km} / \mathrm{h}$ in urban areas, I would worry about an accident, Other people would be impressed if I drove at $65 \mathrm{~km} / \mathrm{h}$ in an urban area and If I drive $65 \mathrm{~km} / \mathrm{h}$ in and urban areas, I would be stopped by the police and fined. All items were measured on a scale from 1 to $7(1=$ strongly disagree to $7=$ strongly agree). The combination of items was $\alpha=.43$ which is less than $\alpha=.70$ and therefore not ac- 
ceptable (Cortina, 1993). In in subsequent analysis the items measuring attitudes were therefore treated as separate items.

The two types of social norms were assessed, namely subjective and descriptive norms. Subjective norm was measured by two items, referring to friends and parent's perceptions of the behaviour and if they approve of it: My friends think it's okay for me riding at $65 \mathrm{~km} / \mathrm{h}$, My parents think it's okay for me riding at $65 \mathrm{~km} / \mathrm{h},(1=$ strongly disagree to $7=$ strongly agree). The combination of items was $\alpha=.43$ and therefore treated separately. The measure of descriptive norms included one item: My friends often drive at $65 \mathrm{~km} / \mathrm{h}$ in an urban area $(1=$ strongly disagree; $7=$ strongly agree).

Control beliefs included three items: More likely to speed if in a hurry; irritated and angry and if it is late at night ( $1=$ not at all likely; $7=$ very likely), $(\alpha=.86)$.

The intention to speed was assessed by two items: In the coming months "I will ride the moped at a speed of $65 \mathrm{~km} / \mathrm{h}$ in an urban area" and "In the coming months it is very likely that I will ride the moped at a speed of $65 \mathrm{~km} / \mathrm{h}$ in an urban built-up area $(1=$ strongly disagree to $7=$ strongly agree $)$, $(\alpha=.94)$.

\section{PWM variables}

Prototype evaluation (imagined) included seven items inspired by Gerrad et al. (2002). The participants were first presented with the following text: "The following questions are about how you perceive other people and what you think is typical. For example, if we can talk about a typical movie star who can be described as successful, good-looking and confident. Now I want you to describe the typical person riding a moped at $65 \mathrm{~km} / \mathrm{h}$ in urban areas with the help of the following statements. How is he or she?". The seven adjectives were measured on a scale from 1 to 7: popular/not popular; stupid/clever, need to impress others/no need to impress others, coward/ tough, boylike/girllike, care about others/do not care about others and timid/ confident.

Prototype similarity was measured by one item, "How similar do you think you are to this typical person?" (1=not very similar; $7=$ very similar). Protype evaluation (impression) was also measured by one item: "What do you think about this person?" (1=do not like at all like; $7=$ like very much to).

Willingness was measured by one item: I would be willing to ride the moped at a speed of $65 \mathrm{~km} / \mathrm{h}$ in a built-up area ( $1=$ strongly disagree; $7=$ strongly agree).

The survey ended with demographic data and how often they had been riding a moped during the last month $(1=$ every day; $2=$ several times a week; $3=$ once a week; $4=$ less than once a week; $5=$ don't know).

\subsection{Data analysis}

By means of the Statistical Package for the Social Sciences (SPSS) a variety of statistical analyses were carried out including: Descriptive statistics (mean, $S D$ ), Pearson's correlation coefficient and hierarchical regression analysis. The level of significance was set at $5 \%$.

\section{RESULTS}

\subsection{Descriptive analyis}

The results show that participants were slightly more willing to speed than agreeing with the statement that they intend to do the same (see Table 1). A large proportion strongly agreed that this involved a risk of being stopped by the police and getting fined. They were also concerned about accidents. They felt that their parents would not accept such behaviour, but that their friends would be more tolerant. In percentage the results showed that $20 \%$ intended to speed whereas $29 \%$ were willing to do the same (scoring $>3$ ). Sixty-nine present would worry about an accident and $79 \%$ believed that they would be stopped and fined by the police. However, despite this, $51 \%$ believed that their friends would speed.

According to the Pearson's correlation coefficients all the TPB variables but also the two variables from the PWM were significantly associated with intention. That speeding in an urban area would be "fun" and that they could identify with somebody who speed was highly correlated with intentions $(r=.53)$. The same applied to control beliefs which indicated that they were more likely to speed if they were in a hurry; irritated and angry and if it is late at night $(r=.56)$. The correlation between willingness and the other variables was also significant and in this case the relationship with that it would be "fun" was even stronger than with intention $(r=.63)$. The results also show that prototype evaluation (impression) had a stronger relationship 
Table 1. Descriptive statistics and correlations.

\begin{tabular}{|c|c|c|c|c|c|c|c|c|c|c|c|c|c|}
\hline Variable & $\mathbf{M}$ & $S D$ & 1 & 2 & 3 & 4 & 5 & 6 & 7 & 8 & 9 & 10 & 11 \\
\hline 1. Intention & 2.21 & 1.81 & & & & & & & & & & & \\
\hline 2. Willing & 2.50 & 1.82 & .63 & - & & & & & & & & & \\
\hline 3. ATT1 & 3.21 & 1.95 & .53 & .63 & - & & & & & & & & \\
\hline 4. ATT2 & 5.17 & 1.96 & -.26 & -.28 & -.23 & - & & & & & & & \\
\hline 5. ATT3 & 2.13 & 1.63 & .23 & .32 & .30 & $-.06^{\mathrm{ns}}$ & - & & & & & & \\
\hline 6. ATT4 & 5.79 & 1.84 & -.18 & -.12 & -.06 & -.24 & $-.06^{\mathrm{ns}}$ & - & & & & & \\
\hline 7. SN1 & 4.43 & 2.26 & .37 & .41 & .53 & -.16 & .26 & $-.06^{\mathrm{ns}}$ & - & & & & \\
\hline 8. SN2 & 2.01 & 1.65 & .36 & .34 & .30 & -.27 & .24 & -.15 & .29 & - & & & \\
\hline 9. DN & 3.59 & 1.99 & .48 & .47 & .45 & -.21 & .30 & $-.02^{\mathrm{ns}}$ & .51 & .25 & & & \\
\hline 10. $\mathrm{CB}$ & 3.56 & 2.08 & .56 & .51 & .59 & -.21 & .22 & $-.07^{*}$ & .48 & .27 & .42 & & \\
\hline 11. Eval & 3.06 & 1.53 & .37 & .50 & .48 & -.31 & .19 & -.15 & .38 & .20 & .34 & .43 & \\
\hline 12. Sim & 2.78 & 1.80 & .53 & .53 & .49 & -.31 & .21 & -.10 & .38 & .27 & .38 & .50 & .56 \\
\hline
\end{tabular}

Note. Scale 1-7 with 1=strongly disagree, not at all likely, not very similar and do not like at all. All correlations are significant at the 0.01 level unless something else is indicated. ATT1=fun; Att2=Accidents; Att3=Impress; Att4=Stopped by the police and fined. SN1=Subjective norm - Friends; SN2=Subjective norm - Parents; DN=Descriptive norm friends; $\mathrm{CB}=\mathrm{Control}$ beliefs index; Eval=Prototype evaluation (impression); $\mathrm{Sim}=$ prototype similarity.

with willingness than intention $(r=.50$ and $r=.37$ respectively). Other results which stands out is the relationship with control beliefs and if it is seen as "fun" and if their friends would accept the behaviour ( $r=.59$ and $r=.48$ respectively). This would then indicate that even if they would speed due to being in a specific mood or when it was late at night, this was also considered to be "fun" and accepted by others.

\subsection{Important factors predicting their intention and their willingness to speed in an urban area}

The present study aimed to examine factors influencing young moped riders to speed in an urban area, including both analytic and heuristic measures. The question was, if young adolescents speeding in an urban area could be considered as deliberate or if it was more spontaneous? Two hierarchical regression analysis were therefore conducted. In the first one, intention was added as the dependant variable and in the second one willingness. The analyses were made in three steps; first the predictors derived from the TPB were included: attitude, subjective norm, descriptive norm and control beliefs. In a second step, prototype evaluation (impression-liked the person) and prototype similarity was added and finally, in a third step, gender. Results are displayed in Table 2 and 3. The variables within the TPB explained $45 \%$ of the variance in intention. All of them were significant, except for the belief that it would result in a crash and that the behaviour would impress others. With reference to subjective norm, parent's acceptance was more important than friends. When the variables derived from PWM were added the model in step 2 it explained $49 \%$ of the variance. In this step, only prototype similarity was significant. In the third step the contribution of gender was not significant.

The results from the second regression analysis presented in Table 3 shows that the variables within the TPB explained $48 \%$ of the variance in willingness. All of them were significant, except for the belief that they would be fined and that friends would accept the behaviour. In this step, the contribution of attitudes (impress) was significant, indicating that those who were willing to speed also believed that it would impress others. In the second step the explained variance increased to $52 \%$ with both prototypes being significant. This would then imply that young mopedists who were willing to speed could identify with a person doing the same (similarity) and that they liked that person (evaluation). In the third step the contribution of gender was not significant. 
Table 2. Hierarchical regression on intention to speed in an urban area.

\begin{tabular}{|c|c|c|c|c|c|c|c|c|c|}
\hline & \multicolumn{3}{|c|}{ Step 1} & \multicolumn{3}{|c|}{ Step 2} & \multicolumn{3}{|c|}{ Step 3} \\
\hline & $B$ & $S E B$ & $\beta$ & $B$ & $S E B$ & $\beta$ & $B$ & $S E B$ & $\beta$ \\
\hline ATT1 (fun) & .20 & .03 & $.21 * * *$ & .17 & .03 & $.18^{* * * *}$ & .16 & .03 & $.17^{* *}$ \\
\hline ATT2 (crash) & -.04 & .02 & -.05 & -.01 & .02 & -.02 & -.01 & .02 & -.02 \\
\hline ATT3 (impress) & .00 & .03 & .00 & .01 & .03 & .01 & .01 & .03 & .01 \\
\hline ATT4 (fined) & -.12 & .03 & $-.12 * * *$ & -.12 & .02 & $-.12^{* * *}$ & -.12 & .02 & $-.12^{* *}$ \\
\hline SN1 (friends) & .05 & .03 & $.06^{*}$ & .05 & .03 & $.07^{*}$ & .05 & .03 & $.07^{*}$ \\
\hline SN2 (parents) & .15 & .03 & $.14 * * *$ & .14 & .03 & $.12 * * *$ & .14 & .03 & $.13^{* *}$ \\
\hline DN (friends) & .21 & .03 & $.24 * * *$ & .19 & .03 & $.22 * * *$ & .19 & .03 & $.22 * *$ \\
\hline CB (index) & .28 & .03 & $.30 * * *$ & .23 & .03 & $.25 * * *$ & .23 & .03 & $.25^{* *}$ \\
\hline Adj $R^{2}$ & & & .45 & & & & & & \\
\hline Evaluation & & & & .06 & .04 & .05 & .06 & .04 & .05 \\
\hline Similar & & & & .25 & .03 & $.24 * * *$ & .24 & .03 & $.24 * *$ \\
\hline Adj $R^{2}$ & & & & & & .49 & & & .49 \\
\hline Gender & & & & & & & .15 & .09 & .04 \\
\hline Adj $R^{2}$ & & & & & & & & & .49 \\
\hline
\end{tabular}

Note: Method=ENTER. $B=$ unstandardized coefficient; $\mathrm{SE}=$ standard error; $\beta=$ standardized regression coefficients; Adj $\mathrm{R}^{2}=$ explained variance in the dependent variable; $\mathrm{ATT}=\mathrm{Attitude}$ SN=Subjective norm; $\mathrm{DN}=$ Descriptive norm; $\mathrm{CB}$ (index) $=$ Control beliefs; Evaluation=Prototype evaluation (impression); Similar=prototype similarity. Scale 1-7 with 1=strongly disagree, not at all likely, not very similar and do not like at all. ${ }^{* *} p<0.001$, * $p<0.05$; Step $1 \mathrm{~F}=95.13$; Step $2 \mathrm{~F}=87.26$; Step $3 \mathrm{~F}=79.69$.

Table 3. Hierarchical regression on willingness to speed in an urban area.

\begin{tabular}{|c|c|c|c|c|c|c|c|c|c|}
\hline & \multicolumn{3}{|c|}{ Step 1} & \multicolumn{3}{|c|}{ Step 2} & \multicolumn{3}{|c|}{ Step 3} \\
\hline & $B$ & $S E B$ & $\beta$ & $B$ & $S E B$ & $\beta$ & $B$ & $S E B$ & $\beta$ \\
\hline ATT1 (fun) & .38 & .03 & $.40 * * *$ & .31 & .03 & $.34 * * *$ & .30 & .03 & $.33^{* * *}$ \\
\hline ATT2 (crash) & -.08 & .02 & $-.09 * * *$ & -.04 & .02 & -.04 & -.04 & .02 & -.04 \\
\hline ATT3 (impress) & .11 & .03 & $.10 * * *$ & .10 & .03 & $.09 * * *$ & .10 & .03 & $.09^{* * *}$ \\
\hline ATT4 (fined) & -.05 & .03 & -.05 & -.03 & .02 & -.04 & -.03 & .02 & -.03 \\
\hline SN1 (friends) & .03 & .02 & .03 & .04 & .02 & .05 & .04 & .02 & .05 \\
\hline SN2 (parents) & .10 & .03 & $.09 * * *$ & .10 & .03 & $.09 * * *$ & .10 & .03 & $.09^{* * *}$ \\
\hline DN (friends) & .15 & .03 & $.17 * * *$ & .13 & .03 & $.15^{* * *}$ & .13 & .03 & $.15^{* * *}$ \\
\hline CB (index) & .14 & .03 & $.15 * * *$ & .08 & .03 & $.09^{* *}$ & .09 & .03 & $.10^{* *}$ \\
\hline Adj $R^{2}$ & & & .48 & & & & & & \\
\hline Evaluation & & & & .16 & .04 & $.13 * * *$ & .16 & .04 & $.13^{* * *}$ \\
\hline Similar & & & & .15 & .03 & $.15^{* * *}$ & .14 & .03 & $.14^{* * *}$ \\
\hline $\operatorname{Adj} R^{2}$ & & & & & & .52 & & & .52 \\
\hline Gender & & & & & & & .18 & .09 & .05 \\
\hline Adj $R^{2}$ & & & & & & & & & .52 \\
\hline
\end{tabular}

Note: Method =ENTER. $B=$ unstandardized coefficient; $\mathrm{SE}=$ standard error; $\beta=$ standardized regression coefficients; Adj $\mathrm{R}^{2}=$ explained variance in the dependent variable; $\mathrm{ATT}=$ attitude; $\mathrm{SN}=$ Subjective norm; $\mathrm{DN}=$ Descriptive norm; $\mathrm{CB}$ (index) $=$ Control beliefs; Evaluation=Prototype evaluation (impression); Similar=prototype similarity. Scale 1-7 with 1=strongly disagree, not at all likely, not very similar and do not like at all. ** $p<0.001,{ }^{*} p<0.05$; Step $1 \mathrm{~F}=106.45$; Step $2 \mathrm{~F}=97.80$; Step $3 \mathrm{~F}=89.53$. 


\subsection{Regression by gender}

The results showed that young men were more willing to speed (scoring $>3$ ) than young women $(33.7 \%$ and $17.7 \%$ respectively). The question was then if they were influenced by the same or different factors. Two separate analysis for young men and women using a multiple regression analysis were therefore conducted. In the first step TPB factors were added. In the second step both general and more specific variables from the PWM were added i.e. prototype evaluation (impression), prototype (similarity) and prototype evaluation (imagined). The latter is how the person perceive other people and what you think is typical. Results significant at the level of $p<.05$ or less are reported and presented in Table 4.

For the young women the variables within the TPB explained $41 \%$ of the variance in willingness. The most significant contribution was that those who were willing to speed believed that it was "fun". Furthermore, they also believed that this was more likely if they were under some form of pressure and if it was late at night. They believed to a greater degree than the others that their parents would accept the behaviour and that their friends behaved in the same way. When the variables within the PWM were added it increased the variance with $2 \%$. Factors explaining their willingness included that they did not consider such a person as stupid, nor that they had a need to impress others or that the behaviour was particularly boylike. In this group they were also more likely to identify with such a person.

For the young men the TPB variables explained slightly more of the variance in willingness (48\%) although the strongest factor was also that it was "fun". Other similarities with young women was that willingness was influenced by parent's acceptance, friend's behaviour and control beliefs. However, some differences could be noted since those who were willing to speed were less likely to believe that it would result in a crash and that they would be fined. They were more likely to believe that the behaviour would impress others and they also believed that their friends would accept the behaviour. When PWM variables were added in the second step the

Table 4. Hierarchical regression on willingness to speed in an urban area, by gender.

\begin{tabular}{|c|c|c|c|c|c|c|}
\hline & \multicolumn{2}{|c|}{$\mathbf{R}^{2}$} & \multicolumn{2}{|c|}{$\beta$ 1st step } & \multicolumn{2}{|c|}{$\beta$ 2nd step } \\
\hline & o & $\hat{\sigma}$ & q & $\hat{\sigma}$ & q & $\hat{\sigma}$ \\
\hline 1 & .41 & .48 & & & & \\
\hline ATT1 (fun) & & & $.33 * * *$ & $.40 * * *$ & $.30 * * *$ & $.34 * * *$ \\
\hline ATT2 (crash) & & & & $-.12 * * *$ & & $-.07 *$ \\
\hline ATT3 (impressed) & & & & $.10 * *$ & & $.09 * *$ \\
\hline ATT4 (fined) & & & & $-.07 *$ & & \\
\hline SN1 (friends) & & & & $.08^{*}$ & & $.09 *$ \\
\hline SN2 (parents) & & & $.10^{*}$ & $.10^{*}$ & $.09^{*}$ & $.11^{* *}$ \\
\hline DN (friends) & & & $.19 * * *$ & $.17 * * *$ & $.21 * * *$ & $.13 * * *$ \\
\hline CB (index) & & & $.21 * * *$ & $.13 * *$ & $.16 * *$ & \\
\hline 2 & .43 & .52 & & & & \\
\hline Protype (1=popular) & & & & & & $-.09 *$ \\
\hline Protype (1=stupid) & & & & & $.11^{*}$ & \\
\hline $\begin{array}{l}\text { Protype (1=no need to } \\
\text { impress) }\end{array}$ & & & & & $.13 * *$ & \\
\hline Protype (1=boylike) & & & & & $.09 *$ & \\
\hline Evaluation & & & & & & $.16^{* * *}$ \\
\hline Similar & & & & & $.11^{*}$ & $.12^{* *}$ \\
\hline
\end{tabular}

Note: Method =ENTER. $B=$ unstandardized coefficient; $\mathrm{SE}=$ standard error; $\beta=$ standardized regression coefficients; Adj $^{2}=$ explained variance in the dependent variable; $\mathrm{ATT}=$ attitude; $\mathrm{SN}=$ Subjective norm; $\mathrm{DN}=$ Descriptive norm; $\mathrm{CB}$ (index) = Control beliefs; Prototype=Prototype evaluation (imagined); Evaluation=Prototype evaluation (impression); Similar=prototype similarity. Scale 1-7 with $1=$ strongly disagree, not at all likely, not very similar and do not like at all. ${ }^{* * *} p<0.001, * * p<0.01$;

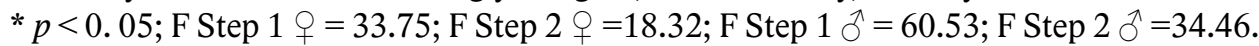


variance increased with $4 \%$. Young men who were willing to speed were more likely to believe that this would make them popular. The person who speeded was somebody they could identify with (i.e prototype similarity) and he/she was also somebody they liked (i.e prototype evaluation, impression).

\section{DISCUSSION}

The aim of the study was to examine factors influencing young moped riders' propensity to speed in an urban area, including two pathways, one intentional and one social reactive. It also aimed to determine if a combination of TPB and PWM increased the prediction of speeding. The final aim was to examine what factors predict young men and women's speeding behaviour, using separate regression analysis.

In general, the results indicated that most of the respondents did not approve of speeding in an urban area and believed that could be stopped by the police and fined. They were also concerned that speeding might result in an accident. Not surprisingly, they did not believe that their parents would accept such behaviour, but that their friends would be more tolerant. Based on the responses, it was also clear that there were some circumstances that might make them drive too fast; if they were in a hurry, irritated or if it was late in the evening.

The results also showed that intention and willingness was highly correlated although the regression analyses demonstrated that they were not always related to the same constructs. The first model used intention as the dependent variable and the second model willingness. In the first step TPB variables were included and in the second step variables based on the PWM were added. The results showed that the first model explained $49 \%$ of the variance and that PWM added $4 \%$. This was slightly less than the second model using willingness as the dependent variable (52\%) but the contribution of PWM was the same.

In both models, the attitude that speeding would be "fun" was important, but it added more to the prediction of willingness than intention. The opposite was found for subjective norm which added more to the prediction of intention than willingness. This would be in agreement with Gibbons et al (2009) who argued that subjective norm is more deliberate and therefore having a stronger link to intention. However, in this study descriptive norm also added more to the prediction of intention than willingness which contradict Gibbons et al (2009) who stated that it would reflect the persons perception and therefore be more heuristic and linked to willingness.

Control beliefs was another variable which was important in both models but more in the prediction of intention. It could be stated that those who intended to speed demonstrated poor self-control, since they were more likely to do the same if they were in a hurry or irritated.

According to the self-control theory (Gottfredson \& Hirschi, 1990) people with low self-control are attracted to behaviour which provides immediate benefits and are easy to execute and exiting. The results from this study warrants some support to this even if control beliefs were not measured in the same way as suggested by Gottfredson and Hirschi (1990) which included six subscales. Control beliefs was correlated with it being "fun" to speed, their friends will accept the behaviour and that their friends also speeded. Nevertheless, it could also be argued that low selfcontrol describes adolescence in general since the prefrontal cortex, which serves a controlling function, is not fully developed until their mid-twenties (Gogtay, \& Geidd, 2004).

The study found that those who were willing to speed were more likely to believe that this behaviour would impress others. Although, this factor only added to the prediction of their willingness to speed. Another interesting difference was that the denial of risk, in this case being fined by the police, was only significant in the first model, i.e. intention to speed. For prototype impression (if they liked this person) it only predicted their willingness to speed. The contribution of PWM variables compares well with other studies (Elliott, et al, 2017; Rivis et al, 2006). Perhaps this would indicate that adolescents speeding behaviour is more reactive than planned, which would be in agreement with several other studies dealing with health-related behaviours (Gibbons et al, 1998).

The next question was whether young men and women were affected by similar variables. The results indicated that young men and women who wanted to indulge in risky behaviour were heavily influenced by one important factor, namely that speeding was "fun". This is consistent with other studies which have found that young drivers would regard speeding as low risk (Knight, Iverson \& Harris, 2013), pleasant (Cestac, et al, 2011) and that it can be exciting (Rowe, et. al., 2016).

Both groups were also influenced by their friend's behaviour and parent's approval. Nonetheless, there were some differences, for instance young wom- 
en who were willing to speed, as opposed to young men, were not influenced by their friend's approval and that it would impress others. Young men who were willing to speed were less likely to believe that it would result in a crash.

When it came to the PWM variables young women who were willing to speed expressed more sympathy towards somebody who did the same than those who were less willing. This meant that they were less likely to believe that such a person was stupid and that they had a need to impress. They would not regard the behaviour as being very "boylike" which might also explain why they could identify with this person. In contrast young men believed that the behaviour would make them popular. Similar results were also presented by Waylen and McKenna (2002) who found a clear difference between boys and girls at the age of 11 in their perception of a person who breaks the rules in traffic. Only the young men believed that it would impress others and that they would be popular. This was also supported by Taubman - Ben-Ari, et al (2015) who found that risky driving would make young males popular.

The behaviour of both young men and women can be explained by the "social identity theory" (Stainton Rogers, 2003). Both young men and women would identify with a person speeding although the consequences of this behaviour are not perceived to be as positive for women as for men. It could therefore be argued that risk taking provides young men with greater status since it is regarded as masculine. This can also explain why young women in this study distanced themselves from describing the behaviour as "boylike". Further interpretations of these results can be that a person achieve a certain status within the group, if he/she conforms to a shared norm (Miller, 2004). For young men this would be the case but perhaps not as much for women.

According to Courtenay (2000) it is important to discuss gender and gender roles otherwise men's propensity to engage in risky behaviour could be seen as natural and inevitable. Instead men are constructing gender when they deny weakness or vulnerability and embrace risk. By doing this they prove to themselves that they are the "stronger" sex which in turn gives them a certain status.

\subsection{Implication for intervention}

In order to increase our understanding of young men and women's driver behaviour two different theo- retical models were used. This combination provided insight into what motivate the behaviour. Instead of simply stating the fact that young men are more likely to be involved in a crash than young women the results from the study helps in highlighting social and psychological factors which predict the same. This would then move beyond being deterministic focusing on hormones etc and instead discussing factors which can be changed. Although gender identity, and indeed the link between being tough and masculine are strong, gender is a construction and can therefore be deconstructed.

In order to achieve this a form of learning is proposed which involves a reflective dialogue between teacher and student. The student should be encouraged to test the likelihood of the statements being discussed and to reflect critically on their past beliefs to see if they need to be modified. According to Mezirow (1997) the learning becomes transformative when past assumptions are perceived as incorrect and when the student acquires so many new views that the balance of the frame of reference changes. In order to achieve this the teacher can work with reflective dialogue, group work, group discussions, role play and case studies. The goal is to develop the student's thinking by exposing opposing opinions and coming up with new ones that are better, both for themselves and others.

The results from this study shows that it is worth discussing speeding and what the pros and cons are. Would it impress others or their friends? The same applies to the notion of being popular and why some young men believe that speeding would make them so? Is that true and why? Since status and being accepted by peers are important the discussion could also be about other ways to become popular and accepted. Since all young men do not speed it is very important to highlight this and increase their status.

\section{CONCLUSIONS}

This study showed that intention and willingness are related but that they are not always predicted by the same constructs. The most important factor is that for adolescents speeding is "fun" but that they are also influenced by friend's behaviour and the image of a person who speeds. Adding willingness, as the dependent variable increased the variance when compared with intention. This might suggest that speeding can be described as a reactive behaviour rather 
than planned. Based on the results from this study it can therefore be concluded that TPB would benefit from the inclusion of PWM variables.

The study also found that although young women were less likely to speed the variables explaining their willingness to speed was fairly similar to that of young men. Both regarded the behaviour as "fun". However, young men were more likely to believe that the action would impress others and that a person who speeds would be popular. The same variables did not explain young women's speeding. Instead friend's behaviour was more important and those who were willing to speed were also less likely to describe this person in negative terms. They were also less likely to describe the behaviour as "boylike" which could explain why it was relatively easy for them to identify with such a person.

It is important to be more specific when dealing with gender and not treat men and women as two distinct groups i.e. one risk seeking and one risk avoiding. This can backfire since it can result in a socalled "stereotype threat". This means that in this case young men are at risk of confirming the negative stereotype about their own group (Cordellieri et al., 2016).

Funding: This study was funded by the Transport Administration.

Conflicts of Interest: The author declares not conflicts of interest.

\section{REFERENCES}

Ajzen, I. (1991). The theory of planned behavior. Organizational Behavior and Human Decision Processes 50: 179-211.

Ajzen, I., \& Fishbein, M. (2005). The influence of attitudes on behaviour. In D. Albarracín, B. T. Johnson \& M. P. Zanna (Red.), The handbook of attitudes (pp. 173-221). Mahwah, NJ, USA: Lawrence Erlbaum.

Albarracín, D., Fishbein, M., Johnson, B. T., \& Muellerleile, P. A. (2001). Theories of reasoned action and planned behaviour as models of condom use: A meta-analysis. Psychological Bulletin, 127, 142-161.

Arata, C. M., Stafford, J., \& Tims, M. S. (2003). High school drinking and its consequences. Adolescence, 38, 567-579

Berg, J., Forward, S., \& Holgersson, S. (2008). Unga på moped - en studie av riskgrupper och riktade polisinsatser för att motverka trimning (Young moped riders - a study of risk-taking and methods used by the police to reduce trimming). VTI rapport 631. Linköping: Statens väg- och transportforskningsinstitut.
Banse, R., Gawronski, B., Rebetez, C., Gutt, H., \& Morton, J. B. (2010). The development of spontaneous gender stereotyping in childhood. Relations to stereotype knowledge and stereotype flexibility. Developmental Science, 13, 298-306.

Blanton, H., Gibbons, F. X., Gerrard, M., Conger, K. J., \& Smith, G. E. (1997). The role of family and peers in the development of prototypes associated with substance use. Journal of Family Psychology, 11(3), 271-288.

Bogaert, A.F., \& Fisher, W.A. (1995). Predictors of university men's number of sexual partners. Journal of Sex Research, 32, 119-130.

Campbell, B. C., Dreber, A., Apicella, C. L., Eisenberg, D. T., Gray, P. B., Little, A. C., Garcia, J. R., Zamore, R. S., \& Lum, J. K. (2010). Testosterone exposure, dopaminergic reward, and sensation-seeking in young men. Physiology \& Behavior, 99, 451-456.

Cestac, J., Paran, F., \& Delhomme, P. (2011). Young drivers' sensation seeking, subjective norms, and perceived behavioral control and their roles in predicting speeding intention: How risk-taking motivations evolve with gender and driving experience. Safety Science, 49, 424-432.

Cordellieri, P., Baralla, F., Ferlazzo, F., Sgalla, R., Piccardi, L., \& Giannini, A. M. (2016). Gender effects in young road users on road safety attitudes, behaviors and risk perception. Frontiers in Psychology, 7, Article number 1412.

Cortina, J. M. (1993). What is coefficient alpha? An examination of theory and applications. Journal of Applied Psychology, 78, 98-104.

de Almeida, R. M., Cabral, J. C., \& Narvaes, R. (2015). Behavioural, hormonal and neurobiological mechanisms of aggressive behaviour in human and nonhuman primates. Physiology \& Behavior, 143, 121-135.

DeJoy, D. M. (1992). An examination of gender differences in traffic accident risk perception. Accident Analysis and Prevention, 24, 237-246.

Duke, S. A., Balzer, B. W., \& Steinbeck, K. S. (2014). Testosterone and its effects on human male adolescent mood and behavior: a systematic review. Journal of Adolescent Health, 55, 315-322.

Eisenegger, C., Haushofer, J., \& Fehr, E. (2011). The role of testosterone in social interaction. Trends in Cognitive Sciences, 15, 263-271.

Elliott, M. A., McCartan, R., Brewster, S. E., Coyle, D., Emerson, L., \& Gibson, K. (2017). An application of the prototype willingness model to drivers' speeding behaviour. European Journal of Social Psychology, 47, 735-747.

Engström, I. (2008). Young drivers and their passengers - Crash risk and group processes (Dissertation Linköping Studies in Behavioural Science No 135). Linköpings Universitet.

Falk, B., \& Montgomery, H. (2007). Developing traffic safety intervention from conceptions of risks and accidents. Transportation Research Part F, 10, 412-427.

Farrow, J. A., \& Brissing, P. (1990). Risk for DWI: A new look at gender differences in drinking and driving influences, experiences, and attitudes among new adolescent drivers. Health Education Quarterly, 17, 213.221. 
Fausto-Sterling, A. (1992). Myths of Gender: Biological Theories About Men and Women. Revised edition. Basic books, New York.

Ferguson, S., Williams, A., Chapline, J., Reinfurt, D., \& De Leonardis, D. (2001). Relationship of parent driving records to the driving records of their children. Accident Analysis and Prevention, 33, 229-234.

Fine, C. (2017). Testosterone Rex: Unmaking the myths of our gendered minds. Icon Books Ltf, UK.

Geber, S., Baumann, E., \& Klimmt, C. (2016). Tailoring in risk communication by linking risk profiles and communication preferences: The case of speeding of young car drivers. Accident Analysis and Prevention, 97, 315-325.

Gerrad, M., Gibbons, F. X., Houlihan, A. E., Stock, M. L., \& Pomery, E. A. (2008). A dual-process approach to health risk decision making - The prototype willingness model. Developmental Review, 28, 29-61.

Gerrard, M., Gibbons, F. X., Benthin, A. C., \& Hessling, R. M. (1996). The reciprocal nature of risk behaviors and cognitions: What you think shapes what you do and vice versa. Health Psychology, 15, 344-354.

Gerrard, M., Gibbons, F. X., Reis-Bergan, M., Trudeau, L., Vande Lune, L. S., \& Buunk, B. (2002). Inhibitory effects of drinker and nondrinker prototypes on adolescent alcohol consumption. Health Psychology, 21, 601-609.

Gibbons, F. X., Gerrad, M., Blanton, H., \& Russell, D. W. (1998). Reasoned action and social reaction: Willingness and intention as independent predictors of health risk. Journal of Personality and Social Psychology, 74, 1164-1181.

Gibbons, F. X., Houlihan A. E., \& Gerrard M. (2009). Reason and reaction: the utility of a dual-focus, dual-processing perspective on promotion and prevention of adolescent health risk behavior. British Journal of Health Psychology,14, 231-48.

Gogtay, N., \& Geidd, J. N. (2004). Dynamic mapping of human cortical development during childhood through early adulthood. http://www.pnas.org/content/101/21/8174.abstract. Proceedings of the National Academy of Sciences of the United States of America.

Gottfredson, M. R., \& Hirschi, T. (1990). A general theory of crime, Stanford, CA, Stanford University Press.

Grace, D. M., David, B. J., \& Ryan, M.K. (2008). Investigating preschoolers' categorical thinking about gender through imitation, attention, and the use of self-categories. Child Development, 79, 1928-1941.

Gregersen, N. P. (2010). Nollvision för tonåringar i trafiken Utopi eller möjlighet? NTF, Stockholm.

Grube, J. W., \& Voas, R. B. (1996). Predicting underage drinking and driving behaviors. Addiction, 91,1843-57.

Guggenheim, N., \& Taubman-Ben-Ari, O. (2015). Can friendship serve as an impetus for safe driving among young drivers? Transportation Research Part F, 30, 145-152.

Harré, N., Field, J., \& Kirkwood, B. (1996). Gender differences and areas of common concern in the driving behaviors and attitudes of adolescents. Journal of Safety Research, 27, 163-173.
Hassan, H. M., \& Abdel-Aty, M. A. (2013). Exploring the safety implications of young drivers' behavior, attitudes and perceptions. Accident Analysis and Prevention, 50, 361-370.

Horvath, C., Lewis, I., \& Watson, B. (2012). The beliefs which motivate young male and female drivers to speed: A comparison of low and high intenders. Accident Analysis and Prevention, 45, 334-341.

Iversen, H. (2004). Risk-taking attitudes and risky driving behaviour. Transportation Research Part F, 7, 135-150,

Knight, P.J., Iverson, D., \& Harris, M.F. (2013). The perceptions of young rural drivers in NSW, Australia of speeding and associated risk: A mixed methods study. Accident Analysis and Prevention, 55, $172-177$.

Mayhew, D. R., Simpson, H. M. \& Pak, A. (2003). Changes in collision rates among novice drivers during the first months of driving. Accident Analysis \& Prevention, 35, 683-691.

Mezirow, J. (1991). Transformative Dimensions of Adult Learning. San Francisco. Oxford: Jossey-Bass Publishers.

Mohamed, M., \& Bromfield, N. (2017). Attitudes, Driving Behavior, and Accident Involvement Among Young Male Drivers in Saudi Arabia. Transportation Research Part F, 47, 59-71

Moore, S., \& Gullone, E. (1996). Predicting adolescent risk behaviour using a personalised costbenefit analysis. Journal of Youth and Adolescence, 25, 343-359.

Oltedal S., \& Rundmo T. (2006). The effects of personality and gender on risky driving behaviour and accident involvement. Safety Science, 44, 621-628.

Oscar Oviedo-Trespalacios, O., \& Scott-Parker, B. (2018). Fast and furious: A neglected issue in health promotion among young drivers. Health Promotion Journal of Australia, 30, 311-316.

Parker, D., Manstead, A.S.R., Stradling, S.G., \& Reason, J.T. (1992). Determinants of Intentions to Commit Driving Violations. Accident Analysis and Prevention, 24, 117-134.

Parsons, J.T., Siegel, A.W., \& Cousins, J.H. (1997). Late adolescent risk-taking: Effects of perceived benefits and perceived risks on behavioral intentions and behavioral change. Journal of Adolescence, 20, 381-392.

Rivis A., Sheeran, P., \& Armitage, CJ. (2006). Augmenting the theory of planned behaviour with the prototype/willingness model: predictive validity of actor versus abstainer prototypes for adolescents' health-protective and health-risk intentions. British Journal of Health Psychology, 11, 483-500.

Rowe, R., Andrews, E., Harris, P. R., Armitage, C. J., McKenna, F. K., \& Norman, P. (2016). Identifying beliefs underlying pre-drivers' intentions to take risks: An application of the Theory of Planned Behaviour. Accident Analysis \& Prevention,89, 49-56.

Rueda-Domingo, T., Lardelli-Claret, P., de Dios Luna-del-Castillo, J., Jiménez- Moleón, J. J., García-Martín, M., \& BuenoCavanillas, A. (2004). The influence of passengers on the risk of the driver causing a car collision in Spain. Analysis of collisions from 1990 to 1999. Accident Analysis and Prevention, 36, 481-489. 
Scott-Parker, B. Watson, B., \& King, M. J. (2009). Understanding the psychosocial factors influencing the risky behaviour of young drivers. Transportation Research Part F, 12, 470-482.

Shope, J. T., \& Bingham, C. R. (2008). Teen Driving: MotorVehicle Crashes and Factors That Contribute. American Journal of Preventive Medicine, 35, 261-71.

Simons-Morton. B. G., Quimet, M. C., Chen, R., Klauer, S. G., Lee, S. E., Wang., \& Dingus, T. A. (2012). Peer influence predicts speeding prevalence among teenage drivers. Journal of Safety Research, 43, 397-403.

Stainton Rogers, W. (2003). Social Psychology: Experimental and critical approaches. Philadelphia: Open University Press.

Summala, H. (1996). Accident risk and driver behaviour. Safety Science. 22, 103-117.

Taubman - Ben-Ari, O., Kaplan, S., Lotan, T., \& Prato, C, G. (2015). Parents' and peers' contribution to risky driving of male teen drivers. Accident Analysis and Prevention, 78, 81-86.

Vollrath, M., Meilinger, T., \& Krüger, H.-P. (2002). How the presence of passengers influences the risk of a collision with another vehicle. Accident Analysis and Prevention, 34, 649-654.

Watters, S. E., \& Beck, K. H. (2016). A qualitative study of college students' perceptions of risky driving and social influences. Traffic Injury Prevention, 17, 122.127.

Waylen, A., \& McKenna, F. (2002). Cradle attitudes - grave consequences. University of Reading. UK.

Weston, L., \& Hellier, E. (2018). Designing road safety interventions for young drivers - The power of peer influence. Transportation Research Part F, 55, 262-271.

Whissell, R. W., \& Bigelow, B. J. (2003). The speeding attitude scale and the role of sensation seeking in profiling young drivers at risk. Risk Analysis, 23, 811-820.

Worchel, S. Rothgerber, H., Day, E. A., Hart, D., \& Butemeyer, J. (1998). Social identity and individual productivity within groups. British Journal of Social Psychology, 37, 389-414. 